WellBeing International

WBI Studies Repository

$9-2007$

\title{
Animal Minds, Cognitive Ethology, and Ethics
}

Colin Allen

Indiana University

Marc Bekoff

University of Colorado

Follow this and additional works at: https://www.wellbeingintlstudiesrepository.org/acwp_asie

Part of the Animal Studies Commons, Comparative Psychology Commons, and the Other Animal Sciences Commons

\section{Recommended Citation}

Allen, C., \& Bekoff, M. (2007). Animal minds, cognitive ethology, and ethics. The Journal of Ethics, 11(3), 299-317.

This material is brought to you for free and open access by WellBeing International. It has been accepted for inclusion by an authorized administrator of the WBI Studies Repository. For more information, please contact wbisr-info@wellbeingintl.org.

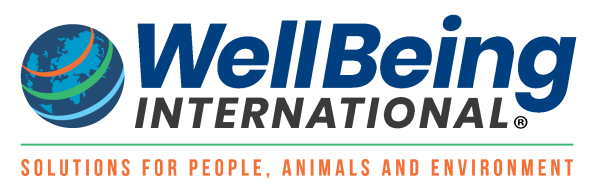




\title{
Animal Minds, Cognitive Ethology, and Ethics
}

\author{
Colin Allen ${ }^{1}$ and Marc Bekoff ${ }^{2}$ \\ ${ }^{1}$ Indiana University \\ ${ }^{2}$ University of Colorado
}

\section{KEYWORDS}

animal cognition, consciousness, ethics, science

\section{$\underline{\text { ABSTRACT }}$}

Our goal in this paper is to provide enough of an account of the origins of cognitive ethology and the controversy surrounding it to help ethicists to gauge for themselves how to balance skepticism and credulity about animal minds when communicating with scientists. We believe that ethicists' arguments would benefit from better understanding of the historical roots of ongoing controversies. It is not appropriate to treat some widely reported results in animal cognition as if their interpretations are a matter of scientific consensus. It is especially important to understand why loose references to "cognitive ethology" by philosophers can signal ignorance of the field to scientists who are more deeply immersed in the relevant literature. Understanding the variety of approaches to cognitive phenomena in animals is essential if such capacities are to form the foundation of scientifically-informed ethical reasoning about animals.

\section{INTRODUCTION}

In Animal Liberation, Peter Singer sought to revolutionize societal treatment of nonhuman animals by arguing that animal agriculture and animal experimentation cause conscious pain and suffering that is real and morally significant. With The Question of Animal Awareness, Donald Griffin sought to revolutionize the science of animal behavior by insisting that questions about animal consciousness should be placed firmly in the foreground of a new program of research he labeled "cognitive ethology." Both proposals immediately evoked a range of reactions, from enthusiasm to virulent attack. In the ensuing three decades little consensus has been reached about either.

Although Singer's arguments about ethical treatment of animals preceded Griffin's arguments about scientific understanding of animals, it is obvious why ethicists concerned with the former should be interested in the latter. Singer himself based the case for animal liberation on scientific evidence of behavioral and neurological homologies between humans and other animals. ${ }^{2}$ Cognitive ethology, by rejecting behaviorist strictures against attributing subjective states of awareness to nonhuman animals, offered the prospect of increased scientific support for the claim that animals are conscious in the ways that matter ethically. 
In the past three decades, animal ethics and cognitive ethology have both diversified significantly. Among ethicists, although some still hold the Benthamite view that conscious experience of suffering is the fundamental moral issue, many now consider a range of cognitive capacities such as desires, prospective planning, and retrospective (or autobiographical) memory to be relevant to questions of what is morally permissible with respect to animals. ${ }^{3}$ In cognitive ethology, conscious awareness has remained a tough nut to crack, but there have been multiple studies on a broad range of cognitive abilities. Not all of these studies share Griffin's perspective on the aims or methods of animal cognition research.

These days the entire field of animal cognition studies enjoys widespread exposure through television documentaries and the science sections of newspapers and magazines. Among the many studies that have recently made it into mainstream media are reports of dolphins apparently recognizing themselves in mirrors, starlings identifying recursive syntax violations, chimpanzees who appear to know what others can see, crows fashioning tools, ${ }^{4}$ monkeys rejecting unfair rewards, ${ }^{5}$ play and moral behavior in animals, ${ }^{6}$ fish rubbing inflamed lips, ${ }^{7}$ and rats laughing when tickled. ${ }^{8}$ Although the media coverage tends to be biased towards results that suggest human-like capacities in animals, there are exceptions, as with the recent coverage of a Norwegian government study denying that lobsters feel pain when immersed in boiling water that was widely reported in many major newspapers. ${ }^{9}$ But on the whole, the public does not need much convincing that science supports the attribution of cognitive and emotional capacities to all vertebrate species, and perhaps some invertebrates too. Nevertheless, scientific skepticism about animal cognition remains a significant factor in policy debates and it is important for philosophers who wish to engage such scientists to have a rich understanding of the origins of their skepticism.

We see at least two areas where more sophistication about the scientific context would be beneficial to ethicists, and philosophers in general:

1. Philosophers' arguments would benefit from better understanding of the historical roots of ongoing controversies. It is not always accurate or helpful to dismiss skeptical questions from scientists about animal minds as a lingering relic of behaviorism or positivism (It may be sometimes accurate, but rarely helpful to winning the argument). Neither is it appropriate to treat some widely reported experiments in animal cognition as if their interpretations are a matter of scientific consensus. It is especially important to understand why loose references to "cognitive ethology" by philosophers can signal ignorance of the field to scientists who are more deeply immersed in the relevant literature.

2. Philosophers need to distinguish more clearly among different features of animal cognition. Some scientists who are highly skeptical of animal consciousness are much less skeptical about notions such as memory, concepts, and attention. They may embrace the possibility of scientific investigation of these aspects of animal cognition while rejecting the association of cognitive ethology with the pursuit of consciousness. They may be more disposed to question behavioral evidence than neural evidence. ${ }^{10}$ Understanding the variety of approaches to phenomena such as learning is essential if such capacities are to form the foundation of scientifically-informed ethical reasoning about animals. ${ }^{11}$

\section{SOURCES OF CONTROVERSY}

"We submit that it is this very goal of investigating animal consciousness that, although grand and romantic, falls far outside the scope of a scientific psychology that has struggled for the better part of the past century to eschew such tantalizing, but ultimately unsubstantiable, analyses of subjective mental experience."12 
"[l]t doesn't matter really how I know whether my dog is conscious, or even whether or not I do 'know' that he is conscious. The fact is, he is conscious and epistemology in this area has to start with this fact."13

"It really is something of a scandal that people's intuitions, in this domain, are given any weight at al."14

"It's important to blend 'science sense' with common sense. I maintain that we know that some non-human animals feel something some of the time, just as do human animals. It's nonsense to claim that we don't know if dogs, pigs, cows or chickens feel pain or have a point of view about whether they like or don't like being exposed to certain treatments. Who are we kidding? Frankly, I think we're kidding ourselves."15

Unsubstantiable? A fact? A scandal? Nonsense to claim that we do not know? As the quotations above show, scientists and philosophers can be found on both sides of the question of animal consciousness. The only fact on which all these authors apparently agree is that the issue is unjustifiably controversial. They differ, of course, on where the blame for the controversy lies.

It is tempting (would be convenient) to dismiss the skeptics in general terms, and we can discern at least four strategies for doing so:

The socio-political strategy: To dismiss the doubts as the product of scientists' vested interest in experimenting on live animals for their livelihoods.

The burden-shifting strategy: To maintain that those who wish to deny mental states to animals bear the burden of proof against common sense.

The demon-dodging strategy: To suggest that such skepticism sets a standard of proof that is too high for any empirical science to meet.

The progressivist strategy: To claim that scientific scruples about animal minds are the result of an undue influence of (old-fashioned) positivistic philosophy of science on behaviorism.

In this essay, we shall have little to say about the socio-political strategy, which we think objectively unlikely to change the minds of skeptical scientists. Similarly, we think the burden-shifting strategy is, in its general form, unlikely to prove persuasive, for common sense has a poor track record when pitched against scientific progress. Appeals to common sense may reinforce popular support, but they will not gain the respect of the many scientists whose opinions remain influential when decisions materially affecting the lives of billions of animals get made. As long as scientific consensus on these matters remains elusive, skeptical attitudes are likely to harden if critics fail to appreciate the intellectual underpinnings of the skeptical position.

The demon-dodging and progressivist strategies are more promising insofar as they engage scientists with issues that are central to their enterprise. Questions about the limits of empirical investigation and about the meanings of theoretical terms are central to the history and philosophy of comparative psychology and ethology and prominent in the training given to students entering these fields. By and large, however, participants in the debate about animal minds (including ourselves in earlier writings) have failed to acknowledge the diversity of approaches within different scientific traditions. It has been easier to stereotype those coming from other perspectives as "behaviorists" or "mentalists" and reject the respective approaches in general outline than to engage with the specific details. 
Our goal in this paper is to try to provide enough of an account of the origins of cognitive ethology to help ethicists to gauge for themselves how to balance skepticism and credulity about animal minds when communicating with scientists.

\section{COGNITIVE ETHOLOGY}

Griffin's term "cognitive ethology" cleverly blended the anti-behaviorism of cognitive science with the evolutionary perspective of classical ethology. But, in fact, Griffin's original approach breaks significantly with both of these approaches. The origins of cognitive science are in the language-oriented tasks that defined Chomskyan linguistics and dominated early research in artificial intelligence and cognitive psychology. As such, at the time Griffin was writing, cognitive science was very much concerned with human intelligence (sometimes even defined as such) and, initially at least, cognitive scientists paid little attention to evolutionary questions. Neither was cognitive science particularly concerned with conscious processing. Computational theories of speech processing described cognitive processes that were assumed to be entirely unconscious, for instance.

Similarly, classical ethology was pursued in ways that were silent about questions of animal consciousness. Konrad Lorenz's popular writings about animal behavior often suggested rich mental lives for animals, ${ }^{16}$ but Niko Tinbergen was openly opposed to the idea that addressing such issues had any scientific utility. ${ }^{17}$ Although ethologists used terms such as "intention movements", they used them quite differently from how they are used in the philosophical literature. "Intention movements" refers to preparatory movements that might communicate what action individuals are likely to undertake next, and not necessarily to their beliefs and desires. Classical ethology was initially fixated on ideas of instinct and innateness and had little to say about learning or behavioral flexibility - the latter category being particularly important to Griffin's arguments for conscious awareness in nonhuman animals. Although Griffin's work was seminal, cognitive ethology soon took on broader significance than the study of consciousness alone. It can be defined as the comparative, evolutionary, and ecological study of nonhuman animal minds, including thought processes, beliefs, rationality, information processing, intentionality, and consciousness.

In response to criticism of the instinct concept, ${ }^{18}$ Tinbergen had identified four overlapping areas with which ethological investigations should be concerned: namely, evolution (phylogeny), adaptation (function), causation, and development (ontogeny). His framework is also useful for those interested in animal cognition. ${ }^{19}$ The methods for answering questions in each of these areas vary, but all begin with careful observation and description of the behavior patterns that are exhibited by the animals under study. The information provided by these initial observations allows a researcher to exploit the animal's normal behavioral repertoire to answer questions about the evolution, function, causation, and development of the behavior patterns that are exhibited in various contexts. For example, the play bows used by all canid species to communicate about play are more stereotyped in coyotes than in wolves or domestic dogs because social play in coyotes is more likely to escalate into an aggressive encounter. ${ }^{20}$ Further analysis of the placement of the bows during play bouts revealed that the bows functioned to communicate about the animals' intentions to engage in play. ${ }^{21}$

For a variety of reasons, however, not every scientist engaged in this kind of work willingly accepts the label "cognitive ethologist."22 Many of them reject it because they regard Griffin's approach as insufficiently experimental - a throwback to the excessive reliance on anecdotal reports of Charles Darwin and George Romanes - or because they regard the kinds of experiments that have been conducted under the banner of cognitive ethology as lacking the adequate experimental controls. It is not our goal here to analyze the merits or demerits of such views. ${ }^{23}$ Rather our point is to explain why philosophers who appeal to "cognitive ethology" to support their ethical views are likely to encounter 
resistance from various scientists who have alternative perspectives. It needs to be understood that not all scientists who investigate animal cognition are cognitive ethologists, not even all who are advocates for treating animals more humanely.

Self-identified proponents of cognitive ethology often fuel the skepticism of others. For instance, they explicitly trace the beginnings of cognitive ethology to Charles Darwin's anecdotal cognitivism ${ }^{24}$ and they continue to argue that anecdotes and anthropomorphism have an important role to play in informing and motivating more rigorous study. ${ }^{25}$ From our present-day perspective, however, it is hard to read Darwin or his protégé George Romanes without having the reaction that they erred too much on the side of credulity. ${ }^{26}$ Darwin appealed to the reports of many "excellent observers" to argue that there are only graded differences in mental capacity among the species. Accounts of insects feature prominently. Darwin's final work on earthworms attributes mental capacities to them that no scientist, to our knowledge, is currently investigating. ${ }^{27}$ Romanes collected and published hundreds of anecdotes about animal intelligence, touting them as a first step towards a more systematic investigation. Romanes never got around to that investigation; thus he is remembered today only for his anecdotal approach, for example a story of ants "rescuing" another ant.

Reacting against Romanes, C. Lloyd Morgan had proposed that "in no case may we interpret an action as the outcome of the exercise of a higher psychical faculty, if it can be interpreted as the outcome of the exercise of one which stands lower in the psychological scale." 28 Morgan thought that consciousness (in different degrees) accompanied both "higher" and "lower" psychical faculties. But his principle, now known as "Morgan's canon," soon became linked to the story of Clever Hans as one of the main rallying points for reformers seeking to eliminate mentalistic notions from psychology and put the study of animal behavior on an experimental footing. Students of animal behavior are brought up on the salutary tale of Clever Hans, a horse who fooled many observers into thinking that he could do arithmetic until it was demonstrated in a controlled experiment that Hans was "simply" reacting to the body language of people who knew the answer. Of course, that Hans was so exquisitely sensitive to the postures of human beings is a fascinating observation in its own right, but one that was largely lost in the ensuing rush to champion the cause of controlled experimentation as an antidote to the "natural" anthropomorphic tendencies of even the most sophisticated observers.

Glimmers of the idea that the scientific study of animal behavior and psychology should be conducted experimentally can be found in the 19th-century, including in Darwin's own work on earthworms. But it is only in the 20th-century that experimental approaches to animal behavior became the norm. Experimentation took two paths. In the laboratories of comparative psychologists, beginning with $\mathrm{E}$. L. Thorndike, there was an emphasis on control and measurement of the factors affecting learning, i.e., change of behavior as a function of external stimuli and rewards. In the laboratories and field work of the classical ethologists, the emphasis was on experiments which attempted to probe the innate or instinctual aspects of animal behavior, i.e., patterns of behavior which are relatively fixed within a given lineage. This difference of emphasis has many roots and many effects. Despite the differences, however, the comparative psychologists and the classical ethologists had, by the middle of the 20th-century, effectively eliminated all explicit investigation of animal minds from the sciences.

Psychology had gone from the study of mind and behavior to being just the study of behavior. Among comparative psychologists, the radical behaviorism of J. B. Watson and B. F. Skinner exerted a strong influence in this respect. But not all comparative psychologists were or are radical behaviorists, and it is a mistake to label them all as such. Nor is it correct to assume that those schooled in behaviorist learning theory think there is no role for cognitive concepts in comparative psychology. ${ }^{29}$ What comparative psychologists do share, regardless of their feelings about Skinnerian radical behaviorism, is an emphasis on the importance of controlled experiments, usually requiring laboratory conditions. 
Meanwhile, many of the second generation of classical ethologists branched out into the fields of behavioral ecology and sociobiology. These branches of biology brought game theoretical approaches and other optimizing models to the biological study of animal behavior. By focusing on strategic outcomes without regard to the psychological mechanisms underlying behavior, these models supported the view that internal causes or subjective states were not essential components for a scientific explanation of animal behavior.

Comparative psychologists and ethologists alike claim to be the intellectual descendants of Darwin. But this means different things to different scientists. Although present-day learning theorists tend to cite Thorndike reverently, emphasizing the search for laws of general learning grounded in basic learning mechanisms that they claim are evolutionarily conserved, they also are well aware of evolved differences. Ethologists tend to emphasize the diversity arising from radiative adaptation of species to their environments, but cognitive ethologists have not managed to carry out a comprehensive program that relates cognitive variation to phylogenetic relationships.

Despite their different starting points, we see comparative psychologists and cognitive ethologists converging on several key points. All agree that the tractability of cognitive questions involves application of a diverse set of comparative methods in order to draw inferences about cognitive states and capacities. Comparative psychologists are becoming increasingly aware of ways in which their experimental apparatuses are not neutral pieces of equipment, but are highly tuned to the animal subjects in ways that implicitly reflect facts about niche-related specialization. ${ }^{30}$ Captive settings are also proving to be important for cognitive investigation of evolved specializations such as seed caching in jays. Although these investigators are still cautious about drawing conclusions about subjective states, they nonetheless are more open to a broad range of cognitive questions than the standard behaviorist vs. mentalist dichotomy would suggest. Thus, for instance, N. S. Clayton and her colleagues have used seed caching to investigate episodic memory in scrub jays. These birds are able to remember what they cached, where they cached it, when they cached it, and who watched them cache it. ${ }^{31}$

While carefully conducted experiments in the laboratory and in the field are often able to control for the influence of variables that might affect the expression of behavioral responses, it is usually the case that there are variables whose influence cannot be accounted for. Field studies may be more prone to a lack of control, because the conditions under which they are conducted are inherently more complex and less controllable. An illustration of the concern for control is found in the explicitly cognitive ethological research of D. L. Cheney and R. M. Seyfarth on the meanings of vocal communication and mental processes of vervet monkeys. ${ }^{32}$ Cheney and Seyfarth played back pre-recorded vocalizations of familiar individuals to other group members to test what other group members knew about these individuals. Although they took pains to use the recordings only under conditions when the recorded animal was not visible or within hearing range of the focal animals of their experiments, these researchers remained concerned about their inability to eliminate "all visual or auditory evidence of the [familiar] animal's physical presence. ${ }^{, 33}$ Under field conditions they could never be sure that the recorded animals could not be seen or heard by the other animals. Arguably, given their goal of understanding "how monkeys see the world," access to stimuli from different modalities may be important to consider. Legitimate worries about whether or not field experiments are adequately controlled cannot be addressed in general terms or rejected as manifestations of excessive skepticism. Specific concerns have to be addressed in the context of the specific experimental inference.

Ethicists who wish to make effective use of cognitive ethology in their arguments against skepticism about animal minds must consider the critics' points of view, and tailor their responses appropriately. Cognitive ethology is by no means a mature discipline whose results can be cited without controversy. There is also 
a long way to go before having an adequate data base from which claims about the taxonomic distribution of various cognitive skills that might be relevant to ethics can be put forth.

\section{WHO SAYS ANIMALS DO NOT SUFFER?}

We have been pushing the idea that to convince anyone of anything, you have to know from which position they are starting. When preaching to the choir, some things can be taken for granted. But quoting scripture will rarely convince an atheist.

This is not to say that the truth or soundness of arguments is relative to an audience - just that their effectiveness is. Neither are we advocating saying whatever it takes to win an argument. Believing $P$, but recognizing that it may be ineffective to use or try to convince the audience of $P$ in an argument, does not license one to say not- $P$ instead. One must instead find a way to give a convincing argument without using either.

Against a background of common-sense ideas about whether nonhuman animals experience pain and suffering, more detailed neurological, physiological, and behavioral studies can help resolve difficult cases. But against a more general skepticism about animal consciousness, ${ }^{34}$ the scientifically agreed upon facts about neural, behavioral, and physiological similarities between humans and other animals may not be convincing at all.

It is tempting to dismiss the most trenchant of skeptics in the way suggested by John Searle (quoted above). One might think it is just obvious that dogs experience pleasure and pain - just look at them wagging their tails, or listen to them whimpering. Suggesting otherwise is in some contexts going to be treated as nonsense - liable to get you laughed out of the room. But in other contexts it is not obvious at all. Tail wagging is hardly likely to convince the skeptical scientist or philosopher who might insist on a higher standard of proof than is set by common sense (and profess to be scandalized by the intuitions of ordinary folk).

The reference to a "higher" standard of proof immediately introduces a value judgment since "higher" suggests "better." And this, indeed, is the way both scientists and philosophers think about their standards. Scientists have a long and successful history of undermining common sense, of showing that things that seem obvious - that the earth does not move for example - are mistakes. Philosophers, with even higher (perhaps impossible?) standards of proof have rather less to show for their much longer history of professional skepticism. But still, by challenging the dogmas of the day, philosophers may help to create an environment in which new ideas can flourish. Nevertheless, it remains an open question: whose standards are the right ones for evaluating answers to questions about animal pain and suffering?

Even this question implicitly begs another question by presupposing something that it should not. Why assume that any single standard of evaluation is the right one? Typically, we apply different standards for different purposes. What counts as knowledge in my kitchen may not count as knowledge in the chemistry lab, and whether I am willing to say that I know whether the soufflé will rise depends on who is asking.

Many people from various walks of life have an intense interest in issues of animal pain and suffering. For many of them, the professional skeptic's extreme view that only humans have conscious experiences can be quickly dismissed. "Does he not have a dog?" they ask, with a dismissive wave of the hand. From this perspective, there is no need to inspect the arguments because the conclusions are so obviously false. Yet if the skeptic is Peter Carruthers, he has a theory of consciousness ${ }^{35}$ - perhaps a wrong one, but a theory nevertheless - which is more than those who wave their hands. Against the background of this 
theory, which links consciousness to higher-order thoughts about thoughts, only certain things would count as evidence of consciousness. Wagging tails is not among them.

How might comparisons between humans and animals prove useful for assessing the experiential states of an animal? Our response should be no surprise by now: it depends who you are talking to. Some people want to be assured that their common sense judgments about animal experiences can be mapped onto physiological and anatomical similarities between humans and nonhuman animals. For such people, such comparisons are likely to be highly useful. Others will want more than this. They might point out, for example, that for any similarity one can present, there are also dissimilarities. Humans have significantly more neural tissue than rats, dogs, or monkeys, presumably allowing more sophisticated forms of cognitive processing. Without a theoretical reason for connecting physiology and behavior to conscious experience, it is hard to say exactly how useful these comparisons are. No matter what one says about the analogies between human and nonhuman physiology, a more detailed description will reveal differences that might be relevant to questions about conscious experience. Without anything more to say, arguments based on similarities can always be undermined by pointing out differences. ${ }^{36}$

This is, of course, a double-edged sword. Anyone wishing to argue that certain disanalogies between humans and animals provide grounds for denying conscious experiences to animals must also give an argument for attributing conscious experience in the one case and not the other. Such an argument is most likely going to have to provide a theoretical reason for linking certain physiological processes to conscious experience, or for thinking that certain forms of sophisticated cognitive mechanisms are required for conscious experience.

Ethicists, like almost everyone else, have typically adopted rather simplistic ideas linking physiology and behavior to function - in this respect they are hardly worse off than almost anyone else writing on this topic. Although critical, this remark is supposed to be constructive, intended to encourage all to be more explicit about the standards of evidence that are in play. Our own view is that greater sophistication about the functions of pain and other conscious states will provide a better framework for assessing the evidence in contexts where the interpretation is in doubt. Common ideas about the function of pain are too unspecific. It is not unusual, for instance, to see it claimed that the capacity to experience adverse states is to protect the animal from harm. This is so generic as to be true also of the immune system, and of various completely unconscious withdrawal reflexes. As such, then, it says nothing about why conscious experiences should be especially implicated in responses to harmful situations, and therefore nothing about why certain responses should be considered as indicating conscious pain or suffering.

Common sense tends to focus on the cries or vocalizations of animals, but there needs to be caution about what is casually inferred from vocalizations. For instance, if a rat receives a mildly painful electric shock to its tail, this produces antinociception (reduced responsiveness to subsequent noxious stimuli) in the rat's tail for up to 10 minutes. But during this same period rats will vocalize more rapidly to the same stimulus. ${ }^{37}$ These results caution against simple reliance on reflexive measures when trying to determine the pain experienced by an animal subjected to an aversive stimulus ${ }^{38}$ and they specifically raise questions about the functional interpretation of rat vocalizations. But this is not to say that vocalizations can never be informative about animal pain. For instance, B. Puppe, et al. analyzed piglet vocalizations before, during, and after unanesthetized castration, and found that high frequency calls associated with stress occurred most during the surgical portion of the procedure. ${ }^{39}$ Recognizing that it is a legitimate scientific question whether any particular animal vocalization provides a measure of conscious pain is not the same as conceding the blanket skeptical view that vocalizations never show anything about pain.

Both the present authors participated in a recent exercise concerning the ethics of research involving animals that was conducted by the United Kingdom's Nuffield Council on Bioethics. We were asked to 
comment on the possibility of defining concepts such as "experience," "distress," "harm," "suffering," and "wellbeing" in relation to humans and animals. We were also asked how these concepts can be distinguished. But these terms are not all on the same level. Anyone looking for a definition of "experience" has rather different worries in mind than someone seeking a definition of "harm" or "wellbeing." The last two concepts can both be defined with respect to non-sentient organisms such as trees (or even, in the case of "harm," for things that are not living at all, such as buildings). Depending on who is asking, different definitions of these terms will be more or less convincing. How important for defining "harm" are notions like consciousness, self-consciousness, or self-awareness? While we can define "harm" without any of these, the resulting notion of harm may not be relevant to those who are interested in ethical questions about the treatment of animals. So even our definitions must be calibrated to the intended audience. $^{40}$

Consultants were also asked to say how these theoretical terms would be applied to three different species used in research: rats, dogs, and primates. But the question is too abstract. Does anyone seriously think that dogs suffer but rats do not? If so, let us see why they think it before deciding how to respond. Or is the question intended more narrowly, e.g., do rats suffer less than dogs when given similar electric shocks? This question has a better chance of being answered without getting sidetracked into dealing with general skeptical worries, since the question itself presupposes the possibility of suffering. If we agree that there is suffering associated with shock, and we can find its physiological, behavioral, and neurological correlates in one species, then we can assess the correlates in other species, or in genetically modified animals, in order to make a comparative judgment. Brain imaging can be used to figure out the extent and ramifications of reactions to painful stimuli. Anyone who insists that none of this adds up to an attribution of suffering to any animal has much more general worries that will have to be addressed on their own terms.

Concepts such as "pain," "suffering," "distress" and "happiness" are regularly applied to animals with a high degree of intersubjective agreement. Is this justifiable? Why not? As often happens in public debates about animal welfare, the Nuffield consultants were not provided with any specific arguments against applying these concepts to animals. Could recordings of activity in an animal's brain help decide their applicability? A justification in terms of neuroanatomical convergence is available, but without knowing the specific source of the uncertainty it is impossible to say whether more brain measurements will convince the skeptic. We do not tell physicians that they must withhold attributions of suffering to each other in the absence of brain measurements, so why should we demand such measures before attributing pain to animals? Is a capacity for verbal self-report the deciding factor? These questions are not intended to short circuit arguments, but to highlight the extent to which the adequacy of any response is hard to assess in the absence of a specific challenge.

\section{BACK TO ETHICS}

Studies which emphasize cognitive sophistication of nonhuman animals are highly congenial to the work of many ethicists. Philosophers working on applied questions about the ethical treatment of animals have increasingly turned to science (and not just the media reports) to bolster their arguments. ${ }^{41}$ The kinds of results offered by cognitive ethology and comparative psychology are attractive to ethicists not just for the fuel they seem to provide for normative claims about the proper treatment of nonhuman animals qua moral patients, but also because some of these results put pressure on some widely held views in ethical theory about the nature of moral agency. Some ethical theories (especially Kantian accounts) build requirements for sophisticated cognitive or linguistic abilities into their accounts of the nature of ethical judgments and actions. Straightforwardly applying such theories would appear to exclude nonhuman animals from the domain of moral agents. But evidence that monkeys reject unfair rewards ${ }^{42}$ or that the give and take of play behavior may foster cooperation and fairness ${ }^{43}$ requires reconsideration of the view 
that moral judgment or action are exclusively human capacities. ${ }^{44}$ Thus, the potential significance of recent scientific work on animal minds for both theoretical and applied ethics is huge. Nevertheless, this work has scientific critics who cannot be dismissed in a generic fashion. It cannot be straightforwardly imported. Rather, the critics' arguments, objections, and suggestions for alternative experiments and explanation must be considered case-by-case.

Among applied ethicists who write about the morality of our treatment of animals credence seems more frequent than skepticism about animal mind. This may be a self-selection effect since those who write on this topic usually do so because they care deeply about how animals are treated. Overly credulous reliance on the kinds of studies mentioned above can make ethical arguments appear weak, especially to some of the more skeptical scientists. ${ }^{45} \mathrm{~A}$ similar point can be made about appeals to common sense, although those who argue that scientific data ("science sense" ${ }^{\text {"46) }}$ and common sense should be considered side-by-side in arguments about how we treat other animals are making a valid point about how such arguments operate in many practical contexts, where there is interest in what the theories imply, but where people must also make decisions based on more immediate and intuitive judgments about what the animals in their care are experiencing.

The demands of practical ethics in the castration barn can make the more skeptical challenges to common sense seem completely ungrounded in any real experience with animals. But, for scientists at least, that skepticism is born of specific failures of common sense. Although some scientists do express a kind of blanket skepticism about animal minds, it is usually the case that this skepticism is rooted in specific criticisms of particular studies. Ethicists would do well to go beyond the progressivist strategy of dismissing scientific reluctance about animal minds wholesale, as the product of bad philosophical arguments about the nature of science, ${ }^{47}$ or the demon-dodging strategy of dismissing scientific reluctance as the product of excessive skepticism that should not be "permitted to infect science." 48 In this paper we have attempted to describe the field of cognitive ethology and related scientific approaches to animal cognition in a way that brings some of the complexity of the field to the fore. Our hope is that doing so will enable ethicists to avoid certain pitfalls that might arise from having too simplistic a classification scheme that identifies all comparative psychologists as strict behaviorists and defenders of animal mind as cognitive ethologists. The bottom line is that when arguing with scientists about animal minds there is no substitute for detailed empirical knowledge of the cases in question. ${ }^{49}$

\section{NOTES}

${ }^{1}$ Donald R. Griffin, "Prospects for a Cognitive Ethology," Behavioral and Brain Sciences 4 (1978), pp. 527-538.

${ }^{2}$ Peter Singer, Animal Liberation, 2nd Edition (New York: Avon Books, 1990), pp. 11-13.

${ }^{3}$ See, for example, David DeGrazia, Taking Animals Seriously: Mental Life and Moral Status (Cambridge: Cambridge University Press, 1996); and G. Varner, In Nature's Interests? (Oxford: Oxford University Press, 1998).

${ }^{4}$ A. Kacelnik, J. Chappell, A. A. S. Weir and B. Kenward, "Cognitive Adaptations for Tool-Related Behaviour in New Caledonian Crows," in E. A. Wasserman and T. R. Zentall (eds.), Comparative Cognition (Oxford: Oxford University Press, 2006), pp. 515-528.

${ }^{5}$ S. F. Brosnan and F. B. M. de Waal, "Monkeys Reject Unequal Pay," Nature 425 (2003), pp. 297-299. 
${ }^{6}$ Colin Allen and Marc Bekoff, "Animal Play and the Evolution of Morality: An Ethological Approach," Topoi 24 (2005), pp. 125-135.

${ }^{7}$ L. Sneddon, V. Braithwaite, and M. Gentle, "Do Fish have Nociceptors: Evidence for the Evolution of a Vertebrate Sensory System," Proceedings of the Royal Society London B, 270 (2003), pp. 1115-1121.

8 J. Panksepp \& J. Burgdorf, “'Laughing' Rats and the Evolutionary Antecedents of Human Joy?" Physiology and Behavior 79 (2003), pp. 533-547.

9 See, e.g., D. Adam, "Scientists Say Lobsters Feel No Pain," Guardian Unlimited, February 8, 2005, http://www.guardian.co.uk/animalrights/story/0,11917,1408050,00.html (accessed on February 6, 2007).

${ }^{10}$ See Marc Bekoff, "Animal Emotions and Animal Sentience and Why They Matter: Blending 'Science Sense' with Common Sense, Compassion, and Heart," in J. Turner and J. D'Silva (eds.) Animals, Ethics and Trade (London: Earthscan Publishing, 2006), p. 27-40; and Marc Bekoff, Animal Passions and Beastly Virtues (Philadephia: Temple University Press, 2006).

${ }^{11}$ See Colin Allen, "Animal Pain," Noûs 38 (2004), pp. 617-643.

12 M. Blumberg and E. A. Wasserman, "Animal Mind and the Argument from Design," American Psychologist 50 (1995), p. 133.

13 John Searle, "Animal Minds," Etica \& Animali 9 (1998), p. 50.

${ }^{14}$ Peter M. Carruthers, Phenomenal Consciousness (Cambridge: Cambridge University Press, 2000), p. 199.

${ }^{15}$ Bekoff, "Animal Emotions and Animal Sentience and Why They Matter," p. 33.

${ }^{16}$ Konrad Lorenz, King Solomon's Ring (New York: Crowell, 1952).

${ }^{17}$ Niko Tinbergen, "On the Aims and Methods of Ethology," Zeitschrift für Tierpsychologie 20 (1963), pp. 410-433.

18 See D. S. Lehrman, "A Critique of Konrad Lorenz's Theory of Instinctive Behavior," The Quarterly Review of Biology 28 (1953), pp. 337-363; and P. E. Griffiths, "Instinct in the '50s: The British Reception of Konrad Lorenz's Theory of Instinctive Behavior," Biology and Philosophy 19 (2004), pp. 609-631.

${ }^{19}$ D. Jamieson and Marc Bekoff, "On Aims and Methods of Cognitive Ethology," Philosophy of Science Association 2 (1993), pp. 110-124.

20 Marc Bekoff, "Social Communication in Canids: Evidence for the Evolution of a Stereotyped Mammalian Display," Science 197 (1977), pp. 1097-1099.

${ }^{21}$ Marc Bekoff, "Play Signals as Punctuation: The Structure of Social Play in Canids," Behaviour 132 (1995), pp. 419-429.

${ }^{22}$ Colin Allen, "Is Anyone a Cognitive Ethologist?" Biology and Philosophy 19 (2004), pp. 589-607.

${ }^{23}$ For critical discussion of Griffin's agenda see Jamieson and Bekoff, "On Aims and Methods of Cognitive Ethology;" and S. J. Crowley and Colin Allen, "Animal Behavior: E. Pluribus Unum?" in M. Ruse (ed.), Oxford Handbook of Philosophy of Biology (Oxford: Oxford University Press, 2007). 
${ }^{24}$ Jamieson and Bekoff, "On Aims and Methods of Cognitive Ethology."

${ }^{25}$ G. M. Burghardt, "Cognitive Ethology and Critical Anthropomorphism: A Snake with Two Heads and Hognose Snakes that Play Dead," in C. A. Ristau (ed.), Cognitive Ethology (San Francisco: Erlbaum, 1991), pp. 53-90; Bekoff, "Animal Emotions and Animal Sentience and Why They Matter;" and Animal Passions and Beastly Virtues; A. Horowitz and Marc Bekoff, "Naturalizing Anthropomorphism: Behavioral Prompts to our Humanizing of Animals," in Anthrozoös, forthcoming.

${ }^{26}$ See Charles Darwin, The Descent of Man and Selection in Relation to Sex (New York: D. Appleton and Company, 1871); George Romanes, Animal Intelligence (London: Routledge \& Kegan Paul, 1882).

${ }^{27}$ But see E. Crist's discussion of Darwin's work in the present context [E. Crist, "The Inner Life of Earthworms: Darwin's Argument and its Implications," in Marc Bekoff, Colin Allen, and G. M. Burghardt (eds.), The Cognitive Animal (Cambridge: The MIT Press, 2002), pp. 3-8].

${ }^{28}$ C. Lloyd Morgan, An Introduction to Comparative Psychology (London: Walter Scott, 1894), p. 53.

${ }^{29}$ See Blumberg and Wasserman, "Animal Mind and the Argument from Design," and T. R. Zentall, "The Case for a Cognitive Approach to Animal Learning and Behavior," Behavioural Processes 54 (2001), pp. 65-78.

${ }^{30}$ For a discussion of the ways in which psychologists' mazes are tuned to rats, see W. Timberlake, "Niche-Related Learning in Laboratory Paradigms: The Case of Maze Behavior in Norway Rats," Behavioural Brain Research 134 (2002), pp. 355-374.

${ }^{31}$ For a review, see N. J. Emery and N. S. Clayton, "The Mentality of Crows: Convergent Evolution of Intelligence in Corvids and Apes," Science 306 (2004), pp. 1903-1907.

32 D. L. Cheney and R. M. Seyfarth, How Monkeys See the World (Chicago: The University of Chicago Press, 1990).

${ }^{33}$ Cheney and Sefarth, How Monkeys See the World, p. 230.

${ }^{34}$ See, e.g., Peter M. Carruthers, "Brute Experience," The Journal of Philosophy 86 (1989), pp. 258-269; and Carruthers, Phenomenal Consciousness.

${ }^{35}$ Carruthers, Phenomenal Consciousness.

${ }^{36}$ See Allen, "Animal Pain" for a more detailed discussion of analogy arguments.

${ }^{37}$ T. E. King, R. L. Joynes, M. W. Meagher, and J. W. Grau, "The Impact of Shock on Pain Reactivity II: Evidence for Enhanced Pain," Journal of Experimental Psychology: Animal Behavior Processes 22 (1996), pp. 265-278; and L. Gruen, "The Morals of Animal Minds," in Marc Bekoff, Colin Allen and G.M. Burhgardt (eds.) The Cognitive Animal (Cambridge: The MIT Press, 2002) pp. 437-442.

${ }^{38}$ Colin Allen, P. N. Fuchs, A. Shriver, and H. Wilson, "Deciphering Animal Pain," in M. Aydede (ed.) Pain (Cambridge: The MIT Press, 2005), pp. 352-366.

39 B. Puppe, P. C. Schön, A. Tuchscherer and G. Manteuffel, "Castration-Induced Vocalisation in Domestic Piglets, Sus scrofa: Complex and Specific Alterations of the Vocal Quality," Applied Animal Behavior Science 95 (2005), pp. 67-78. 
${ }^{40}$ It is not possible to turn to science for resolution because such terms, if they are defined at all, are done so only controversially.

${ }^{41}$ See, e.g., James Rachels, Created from Animals (Oxford: Oxford University Press, 1990); DeGrazia, Taking Animals Seriously; Varner, In Nature's Interests?

${ }^{42}$ Brosnan and de Waal, "Monkeys Reject Unequal Pay."

${ }^{43}$ Allen and Bekoff, "Animal Play and the Evolution of Morality."

${ }^{44}$ See also Gruen, "The Morals of Animal Minds."

${ }^{45}$ Colin Allen, "Ethics and the Science of Animal Minds," Theoretical Medicine and Bioethics 27(2006), pp. 375-394.

${ }^{46}$ Bekoff, "Animal Emotions and Animal Sentience and Why They Matter."

${ }^{47}$ Bernard Rollin, The Unheeded Cry (Oxford: Oxford University Press, 1989).

${ }^{48}$ D. Jamieson, Morality's Progress (Oxford: Oxford University Press, 2002), p. 68.

${ }^{49}$ We would like to thank Robert Francescotti and Gary Steiner for their comments on earlier drafts of this essay. 